\title{
Taumatic Emergencies of the External Genital Organs
}

\author{
Avion Kouassi Patrice ${ }^{*}$, Akassimadou N'diamoi1 ${ }^{1}$, Ouattara Fatoumata ${ }^{2}$, Aguia Brice1, \\ Zouan Fredy', Alloka Venance1, Camara Sadia1, Bony Gnissan', Kramo Nykan³, Anzoua Kacou4, \\ Dje Koffi ${ }^{1}$
}

\author{
${ }^{1}$ Department of Urology, University Hospital Center of Bouake, Bouake, Ivory Coast \\ ${ }^{2}$ Laboratory of Anatomy, Department of Urology, University Hospital Center of Treichville, Abidjan, Ivory Coast \\ ${ }^{3}$ Department of Urology, University Hospital Center of Cocody, Abidjan, Ivory Coast \\ ${ }^{4}$ Department of General Surgery, University Center of Bouake, Bouake, Ivory Coast \\ Email: *avionkouassi@yahoo.fr, ndiamoi74@yahoo.fr, hadja_ouat@yahoo.fr, donbricofr@gmail.com, \\ docteurzouan@gmail.com, venancedagotchaka@gmail.com, docteur.ben.sadia.93@gmail.com, ubony07@gmail.com, \\ felicite.moke@gmail.com, ^ankib7@yahoo.fr, djekoff1958@gmail.com
}

How to cite this paper: Patrice, A.K., N'diamoi, A., Fatoumata, O., Brice, A., Fredy, Z., Venance, A., Sadia, C., Gnissan, B., Nykan, K., Kacou, A. and Koffi, D. (2021) Taumatic Emergencies of the External Genital Organs. Open Journal of Urology, 11, 214-225.

https://doi.org/10.4236/oju.2021.116019

Received: April 2, 2021

Accepted: June 18, 2021

Published: June 21, 2021

Copyright $\odot 2021$ by author(s) and Scientific Research Publishing Inc. This work is licensed under the Creative Commons Attribution International License (CC BY 4.0).

http://creativecommons.org/licenses/by/4.0/

\begin{abstract}
Background: The traumas of scrotum are often traumas caused by accidents on the public highway or in sport. However, fractures of the penis are secondary to a direct trauma to the penis with rupture of the albuginea causing hematoma, pain and deviation of the penis. Animal bites are rare. Purpose: To describe the management of traumatic emergencies of the external genital organs at the CHU Bouaké. Patients and Methods: Retrospective and descriptive study on the patients treated at Bouaké University Hospital for traumatic emergencies of the external genital organs during the period from January 01, 2012 to December 31, 2018. The parameters studied were epidemiological, clinical and therapeutic. Results: The study period registered 26 patients. The mean age was 34.5 years, Closed trauma to the scrotum was a frequent reason with $30.8 \%$, the trauma sat on the scrotum in $53.8 \%$, the penis in $42.3 \%$, the vulva in $3.8 \%$ of cases. The circumstances of discovery of trauma to the penis were dominated by coitus missteps (45.5\%), on the stock exchange and vulva by accidents on the public highway (60.8\%). Scrotal swelling was the frequent clinical sign (26.9\%). Treatment was dominated by surgery in $92.30 \%$. Seven patients $(29.16 \%)$ underwent exploratory scrototomy associated with hematoma evacuation, five patients (20.83\%), a simple trimming, five patients $(20.83 \%)$, an evacuation of the hematoma associated with a cavernous suture, one patient (4.16\%), a trimming associated with a suture of the vulva, one patient (4.16\%), a trimming associated with a right orchiectomy. The hospital stay was less than 5 days. The course was simple in $92.30 \%$
\end{abstract}


of the cases; two patients (7.7\%) had complications such as testicular necrosis and atrophy which have been treated by orchidectomy. Conclusion: Traumatic emergencies of the external genitalia are rare but serious. Treatment is dominated by surgery.

\section{Keywords}

Orchidectomy, Scrototomy, Testicle, Trauma, Vulva

\section{Introduction}

Traumatic emergencies of the external genitalia are relatively uncommon and affect young people [1]. These traumas represent less than $1 \%$ in Africa [1], 8\% $10 \%$ in Europe [2], 2\% - 10\% Asia [3], 1\% America [4] and 1.9\% in the Middle East [5]. The etiologies are multiple and the lesions may involve the penis and/or the scrotal contents (testicle, epididymides, cord) in men and the vulva in women. The diagnosis of these injuries is most often clinical in the case of open trauma or fracture of the penis, and may involve ultrasound in the case of a large posttraumatic bursa [2]. They may lead to urinary complications and sequela (erectile dysfunction, curvature of the penis during erection, urethral stricture, testicular atrophy) and serious psychological harm [2]. The management of external genitalia trauma is done in an emergency setting and may include trimming in case of a wound or surgical exploration of the traumatized bursa and finally cavernous suture for penile fractures [3]. This management strategy therefore requires a rigorous clinical evaluation with a precise and complete lesion assessment. Treatment must be early to minimize complications and sequela. The aim of our study was to describe the epidemiological, clinical and therapeutic aspects of traumatic emergencies of the external genitalia in the urology department of the University Hospital of Bouaké.

\section{Patients and Methods}

This is a retrospective and descriptive study which took place in the urology department of the university hospital of Bouake. The study took place from January 1, 2012 to December 31, 2018, during which we collected all cases of traumatic External Genitalia Organs (EGO) emergencies that were treated in the department. The study period registered 26 patients. The study included male and female patients of all ages who were treated medically or surgically for EGO trauma emergencies. There were no exclusion criteria. The parameters studied included: socio-demographic data: (age, profession, sex), clinical: (circumstances of occurrence, aetiology, consultation time, site of injury, associated injuries), paraclinical (imaging), therapeutic (surgical procedure, evolution, postoperative complications, hospitalization time). The data were collected from the patients' files, a survey form and the register of surgical reports of patients operated on for traumatic emergencies at the EGO. All data were entered into the WORLD 
software and processed with Epi info 2.10.

\section{Results}

\subsection{Epidemiology}

The average age of the patients is 34.5 years with extremes of 16 years to 52 years. Table 1 shows the epidemiological characteristics of the patients studied; the patients were predominantly male $(96.23 \%)$ and almost half were over 30 years old. Most were Farmers with $38.46 \%$. The majority was married (69.23\%) and the illiterate ones were (46.23\%).

Table 1. Epidemiological characteristics of patients.

\begin{tabular}{|c|c|c|}
\hline Settings & Effective $(n=26)$ & Percentage (\%) \\
\hline \multicolumn{3}{|l|}{ AGE GROUPS (YEAR) } \\
\hline $16-28$ & 3 & 11.53 \\
\hline $29-35$ & 17 & 65.38 \\
\hline $36-45$ & 3 & 11.53 \\
\hline 45 and over & 2 & 7.69 \\
\hline \multicolumn{3}{|l|}{ SEX } \\
\hline Male & 25 & 96.15 \\
\hline Female & 1 & 3.84 \\
\hline \multicolumn{3}{|l|}{ PROFESSION } \\
\hline administrator & 1 & 3.84 \\
\hline merchant & 2 & 7.69 \\
\hline Student & 2 & 7.69 \\
\hline Teacher & 4 & 15.38 \\
\hline mechanic & 2 & 7.69 \\
\hline Plumber & 1 & 3.84 \\
\hline Farmer & 10 & 38.46 \\
\hline unemployed & 2 & 7.69 \\
\hline Breeder & 2 & 7.69 \\
\hline \multicolumn{3}{|l|}{ CIVIL STATUS } \\
\hline Married & 18 & 69.23 \\
\hline Single & 5 & 19.23 \\
\hline Widower & 3 & 11.53 \\
\hline \multicolumn{3}{|c|}{ LEVEL OF EDUCATION } \\
\hline Primary School & 5 & 19.23 \\
\hline Secondary School & 4 & 15.38 \\
\hline Higher Education & 5 & 19.23 \\
\hline Illiterate & 12 & 46.15 \\
\hline
\end{tabular}




\subsection{Clinic}

\subsubsection{Reason for Consultation}

Closed scrotal trauma was the most frequent reason for consultation with $30.8 \%$.

Table 2 shows that closed trauma to the penis is the second reason for consultation with $26.9 \%$. However, open traumatism of the scrotum and penis comes third (23.1\%) and fourth (11.5\%) respectively. Very few patients consult a doctor for scrotal sore $(3.8 \%)$ or vulvar folds $(3.8 \%)$.

\subsubsection{Occurred Circumstances}

1) Penis

The circumstances in which penile injuries occurred were dominated by coital slips with $45.5 \%(\mathrm{n}=5$; Table 3$)$.

2) Bursa

The circumstances of occurrence of trauma to the bursa are dominated by road traffic accidents with $60 \%(n=6$; Table 4$)$.

Table 2. Dispatching of patients according to reason for consultation.

\begin{tabular}{ccc}
\hline Reason for consultation number Percentage & Number & Percentage \\
\hline Open penile trauma & 3 & 11.5 \\
Closed penile trauma & 7 & 26.9 \\
Closed scrotal trauma & 8 & 30.8 \\
Open scrotal trauma & 6 & 23.1 \\
Vulvar wound & 1 & 3.8 \\
Scrotal wound & 1 & 3.8 \\
Total & 26 & $100 \%$ \\
\hline
\end{tabular}

Table 3. Dispatching of patients according to the circumstances of occurrence.

\begin{tabular}{ccc}
\hline Circumstances of occurrence & Number & Percentage \\
\hline Road traffic accidents & 3 & 27.3 \\
Coitus slip & 5 & 45.5 \\
Dog bite & 1 & 9.1 \\
Firearm & 2 & 18.2 \\
Total & 11 & $100 \%$ \\
\hline
\end{tabular}

Table 4. Dispatching of patients according to the circumstances of occurrence of trauma to the bursa.

\begin{tabular}{ccc}
\hline Circumstances of occurrence & Number & Percentage \\
\hline Road traffic accidents & 9 & 60.0 \\
Falls with impaction & 3 & 20.0 \\
Entrapment & 1 & 6.7 \\
Firearm & 2 & 13.3 \\
Total & 15 & $100 \%$
\end{tabular}


3) Vulva

Only one case of trauma to the vulva due to a road accident was noted $(\mathrm{n}=1$; $3.84 \%)$.

\subsubsection{Delay of Consultation}

The majority of patients consulted within 24 hours of the trauma $(n=23$; $88.5 \%)$.

\subsubsection{Site of Trauma}

Trauma was predominantly to the scrotum with $53.8 \%$ in men $(n=14)$.

\subsubsection{Clinical Signs}

Scrotal swelling predominated with $26.9 \%(n=6$; Table 5$)$.

\subsection{Paraclinic}

- Six (6) patients had an ultrasound scan (23.07\%).

- Seventeen (17) patients had an X-ray of the pelvis (65.38\%).

\subsection{Treatment}

\subsubsection{Type of Treatment}

The majority of patients received surgical treatment with $92.30 \%(n=24)$.

\subsubsection{Type of Anaesthesia}

Loco-regional anaesthesia was the main route of anaesthesia with $91.66(n=22)$.

\subsubsection{Per-Operative Lesions}

Intraoperatively, non-expansive scrotal haematoma accounted for $29.16 \%$, fracture of the corpora cavernosa accounted for $20.83 \%$ and superficial wounds of the penis and scrotum accounted for $20.83 \%$ (Table 6).

\subsubsection{Surgical Procedures}

Exploratory scrototomy associated with evacuation of scrotal hematoma were the most common surgical procedures performed on patients with $29.16 \%$. Table 7 shows that simple trimming and evacuation of the hematoma followed

Table 5. Dispatching of patients according to clinical signs.

\begin{tabular}{ccc}
\hline Clinical signs & Number & Percentage \\
\hline Scrotal pain & 1 & 3.8 \\
Small and/or large lip wound & 1 & 3.8 \\
Penile pain & 3 & 11.5 \\
Swelling of the penis & 6 & 23.1 \\
Sore glans & 3 & 11.5 \\
Scrotal swelling & 7 & 26.9 \\
Testicular avulsion & 1 & 3.8 \\
Testicular fracture & 4 & 15.4 \\
Total & 26 & $100 \%$ \\
\hline
\end{tabular}


Table 6. Dispatching of patients according to intraoperative findings.

\begin{tabular}{ccc}
\hline Intraoperative lesions & Number & Percentage \\
\hline Testicular albuginea wound & 4 & 16.16 \\
Testicular avulsion & 1 & 4.16 \\
Fracture of the corpora cavernosa & 5 & 20.83 \\
Superficial wound of scrotum and penis & 5 & 20.83 \\
Dislocating wound of the vulva & 1 & 4.16 \\
Testicular fracture & 1 & 4.16 \\
Non-expansive haematoma of scrotum & 7 & 29.16 \\
Total & 24 & $100 \%$ \\
\hline
\end{tabular}

Table 7. Dispatching of patients according to surgical procedure.

\begin{tabular}{ccc}
\hline Surgical procedure & Number & Percentage \\
\hline Trimming + suture of the albuginea & 4 & 16.16 \\
Trimming + haemostasis & 1 & 4.16 \\
Evacuation of the haematoma + cavernous suture & 5 & 20.83 \\
Simple trimming & 5 & 20.83 \\
Suture trimming of the small and large lip of the vulva & 1 & 4.16 \\
Trimming + right orchidectomy & 1 & 4.16 \\
Exploratory scrototomy + evacuation of scrotal haematoma & 7 & 29.16 \\
Total & 24 & $100 \%$ \\
\hline
\end{tabular}

by suturing of the cavernous bodies each represented $20.83 \% .16 .16 \%$ of the patients benefited from a trimming of the albuginea wound associated with a suture. A patient underwent a trimming associated with a right orchiectomy (4.16\%). The only woman benefited from a trimming associated with a suture of the vulva (4.16\%).

\subsubsection{Post-Operative Treatment of Associated Lesions}

Post-operatively, all patients who had undergone suture of the corpora cavernosa received oral medication based on diazepam at a dose of $10 \mathrm{mg}$ per day for a fortnight, and non-steroidal anti-inflammatory drugs for a week. They also received probabilistic antibiotic therapy with cephalosporin until the eighth day.

The dog-bitten patient had received rabies prevention, tetanus sero-vaccination and broad-spectrum antibiotic therapy.

Two patients had associated injuries.

There was a traumatic rupture of the urethra and a fracture of the pelvis (7.69\%) $(n=2)$. The treatment consisted of an end-to-end suture of the urethra on a catheter and an orthopaedic treatment for the pelvic fracture.

\subsubsection{Duration of Hospitalization}

More than half of the patients had a hospital stay between [0 and 5 days] after 
treatment, $65.4 \%(\mathrm{n}=17)$.

IV-7-Follow-up of the treatment.

One trophic complication (testicular atrophy) and one infectious complication (testicular necrosis) were observed post-operatively. Orchidectomy was performed to treat the testicular necrosis as well as the testicular atrophy in both patients.

\section{Discussion}

In our study, the minimal age of the patients was 34.5 years with extremes of 16 and 52 years. The young age has been reported by several authors in the literature. Bah in Senegal reported in his study an average age of 37 years [6]. Ouattara in Benin noted an average age of 32.3 years [7]. Djè in Côte d'Ivoire found an average age of 27.8 years [8]. The averages confirm on the one hand that this type of lesion concerns the most active population and on the other hand that young people constitute the most important part of the populations of developing countries. Trauma to the external genitalia is a male prerogative and almost all authors agree on this characteristic [8] [9]. 96.2\% of our study involved men. This predominance of males was noted by Dekou, in his study of 27 cases of trauma to the genital-urinary system, who reported 26 male patients out of a series of 27 patients [1]. This strong male predominance in our series could be explained by the greater exposure of men to public road accidents. We noted one case of trauma to the vulva. This is a rare case and this rarity has been noted in the literature [8]. In our series, closed scrotal trauma was the most frequent reason for admission with $30.8 \%$. This observation was made by Coulibaly in Mali [9], and Kambou in Burkina-Faso [10]. Open trauma was infrequent as reported in the literature [10], most often secondary to a firearm. The circumstances of occurrence of trauma to the bursa and vulva were dominated by road accidents with 63.6\%. Our results are in line with those of Kambou in Burkina Faso [10] and Djè in Côte d'Ivoire [8], who found 45\% and 75.6\% respectively. These different results show that public road accidents are the greatest source of trauma. The main circumstance for the occurrence of penile trauma was coitus error, i.e. $36.4 \%$. This result is similar to the literature [11] [12] [13]. The clinical symptomatology of trauma to the genital-urinary system is well known [6] [7]. It consists of:

- A haematocele which is clinically expressed as an enlarged, normally colored;

- A scrotal haematoma which is characterized by an enlarged, ecchymotic, dark red bursa on pale skin. Sometimes it is a localized deformity.

In our series, the clinical symptomatology was dominated by scrotal swelling in $26.9 \%$ followed by penile swelling in $23.1 \%$.

Our results corroborate those of Coulibaly in Mali [9] and Andry in Switzerland [14]. The increase in the volume of the scrotum could be explained by the violence of the trauma on the scrotum on the one hand, and by the presence of a scrotal haematocele or haematoma on the other. As for the swelling of the penis, it can be explained by the presence of a haematoma opposite the fracture site of 
the corpora cavernosa. From a paraclinical point of view, ultrasound of the bursa is necessary because the physical examination makes it difficult to diagnose lesions of the epididymis, the testicles or the cord, and above all because it is very sensitive due to the pain. Combined with Doppler, it can show areas of localized ischaemia in the case of compressive haematocele, intra-testicular haematoma or rupture of the albuginea [6]. However, its specificity is not perfect, sometimes leading to surgical exploration to make a complete assessment of the lesion [15]. In our work, the diagnosis was mainly made on the basis of clinical findings followed by an emergency operation. Ultrasound was not systematic. Six patients (23.07\%) underwent scrotal ultrasound. Our attitude is in line with that of several authors, notably Djè [8] and Coulibaly [9], who recommend emergency surgical exploration except in cases of moderate trauma. This management would reduce the risks of complications and sequela. The therapeutic attitude to bursal trauma is variable and depends above all on the presence or absence of a haematocele on clinical examination [10]. Thus, in the absence of a haematocele and in the presence of an intact testicle on ultrasound, the medical treatment consists of analgesics, non-steroidal anti-inflammatory drugs in the absence of contraindication of gastro duodenal ulcers, antibiotic coverage, anti-tetanus sero-vaccination associated with suspension of bursaries [10], as was the case for two (2) of our patients, i.e. 7.7\%. In our series, we used local-regional anaesthesia in $91.66 \%$ of cases. We chose spinal anaesthesia because of its advantages, which allow surgery to be performed with ease and comfort [16]. Surgical management consisted of an exploratory scrototomy followed by emergency evacuation of a scrotal haematoma in $29.16 \%$ of cases. This attitude, motivated by the acute traumatic bursa, has been noted by other authors [17] [18]. Our approach corroborates the rule according to which in the case of an acute large bursa, surgical exploration should not be delayed. In our series, all patients admitted for fracture of the corpora cavernosa were approached by circumferential sub coronal incision, because it allows an exhaustive diagnosis of the lesions. Evacuation of the haematoma followed by haemostasis and repair of the albuginea was done with 3/0 Vicryl using separate stitches followed by closure of the skin with separate stitches; a dry dressing was done in $45.5 \%$ of cases, i.e. 5 cases. Postoperatively, all patients received oral medication based on diazepam at a dose of $10 \mathrm{mg}$ per day for a fortnight, and non-steroidal anti-inflammatory drugs for a week. Probabilistic antibiotic therapy was prescribed in our series based on cephalosporin until the eighth day after surgery as some authors [17] [18]. All patients admitted for open trauma received trimming. One patient had orchiectomy on the right side and trimming. Our treatment was due to the fact that the patient presented with open gunshot trauma to the scrotum with disruption of the right testicle. We performed trimming plus haemostasis in one patient due to traumatic avulsion of the testis. Dekou reported four (4) cases of orchiectomy in his study of trauma to the genitourinary system [1]. This finding reflects the violence of the trauma. Our series reports a case of open trauma to the vulva fol- 
lowing a road traffic accident. It was a perineal impaction against the ground. Our management consisted of trimming and suturing of the labia minor and major with 3/0 Vicryl. This reconstructive surgery was performed in collaboration with gynaecologists. Trauma to the external genitalia involving the vulva is extremely rare [19]. The only case reported in seven years of practice confirms this rarity. Animal bites are rare as evidenced by our study but potentially serious [20]. Wolf et al. report four cases of dog bites [19]. Cummings and Boullier reported eight (8) cases treated for scrotal dog bites [20]. However, in the largest series in the literature, Gomes et al. report ten (10) new cases: eight (8) cases were attacked by dogs, one by a horse and one by a donkey [21]. The morbidity is directly related to the severity of the bite and the delay in consultation. These animal bites carry a triple infectious risk: bacterial, tetanic and rabies [15]. Broad spectrum antibiotic therapy should be administered. In our series, one case of dog bite was observed. The bite involved the body of the penis. Wound trimming combined with anti-rabies prevention and anti-tetanus sero-vaccination were carried out according to the vaccine recommendations [21]. The most common bacteria isolated in animal bites are streptococci and staphylococci, Escherichia coli, associated with anaerobic germs. In our case, no germ was identified, hence the choice of broad-spectrum antibiotic therapy. In our series, two patients had associated lesions. It was a traumatic rupture of the urethra and a fracture of the obturator frame, i.e. $7.69 \%$. The bone lesion was managed by orthopaedic surgeons. The urethral injury was not treated as an emergency. It was done as a delayed emergency as recommended by Leguillou in Bordeaux and Gueye in Dakar between the 8th and 10th day [22] [23] and Diallo in Conakry [24]. Our patient was operated on as a delayed emergency after organization of the lesions and at a distance from the inflammatory and infectious processes. This approach of management at a distance from the trauma was that adopted by Dje and Fall [8] [25]. In our series, more than $60 \%$ of patients had a hospital stay of less than five days after treatment. Our duration is in line with that of Coulibaly in Mali [9]. However, some authors such as Kambou et al. in Burkina Faso [10] reported a longer hospital stay of 40.4 days after treatment. The postoperative period was marked by necrosis of the contralateral testicle in a patient who had undergone a right orchiectomy following a gunshot trauma with testicular damage. We performed a second orchiectomy; this unfortunate situation could be explained by microscopic lesions of the cord elements of the left testicle which would have led to secondary ischaemia and then to necrosis of the testicle. This highlights the importance of informing any patient with open bursal trauma of the risks of possible castration and its consequences. According to Bah et al. [15], the possibility of sperm conservation should be considered with the patient. In our case, this option had been proposed to him but he did not consider it appropriate, as he had already fathered 8 children. The possibility of sperm conservation for assisted reproduction was of lesser importance. We observed testicular atrophy which was managed by preventive left orchiectomy. This post bursal trauma 
complication has been observed in approximately $50 \%$ of patients in the series by Cross et al. [26]. The mechanisms of occurrence of testicular atrophy are not well known: post-traumatic lesions of the micro-vascularization of the testis; ischaemia by compression due to oedema and haematoma and autoimmune mechanisms are mentioned in the literature [27]. However, this study has limitations which must be taken into account when interpreting the results. As this is the retrospective nature with significant loss of information, its relatively small size does not give it sufficient statistical power.

\section{Conclusion}

Taumatic emergencies of the external genital organs are uncommon, but it is potentially serious because it can lead to urinary or sexual complications with major consequences for fertility. These injuries are rare in women and very frequent in men. The diagnosis is most often based on clinical examination. However, clinical examination is often difficult because of pain and/or swelling, hence the importance of ultrasound. Trauma to the bursa is most often encountered in road accidents. As for penile trauma, it is secondary to a false step in the coitus and emergency treatment is surgical in most cases. In women, surgical management must be carried out in a multidisciplinary context involving urologists, gynaecologists and psychologists of both sexes. Animal bites of external genital organs are rare but serious and carry a significant infectious risk. Morbidity is related to the severity of the bite and the delay in consultation. Surgical treatment must always be combined with medical treatment and vaccination. Complications and sequela of EGO trauma are formidable. These complications must be explained to the patient before treatment in order to reduce the medico-legal problems associated with trauma.

\section{Ethical Clearance}

The patients were informed and agreed to participate in the study, and their anonymity was preserved.

\section{Conflicts of Interest}

The authors declare that they have no ties of interest.

\section{References}

[1] Dekou, A., Konan, P.G., Kouame, B., Vodi, C., et al. (2008) Les traumatismes de l'appareil génito-urinaire: Aspects épidémiologiques et lésionnels. African Journal of Urology, 14, 105-113. https://doi.org/10.1007/s12301-008-0001-4

[2] Josse, P., Van der Vlies, C.H. and Golings, J.C. (2015) Routine Urinalysis in Patients with Ablaut Abdominal Trauma Mechanism Is Not Valuable to Detect Uroginital Injury. Emergency Medicine Journal, 32, 119-123. https://doi.org/10.1136/emermed-2013-202651

[3] Heon, J.K., Young, J.P. and Yun, S.S. (2014) Traumatic Penile Injury: From Circumcision Injury to Penile Amputation. BioMed Research International, 2014, Ar- 
ticle ID: 375285. https://doi.org/10.1155/2014/375285

[4] Deurdulian, C., Mittelstaedt, C.A., Chong, W.K. and Feelding, J.R. (2007) US of Acute Strotal Trauma: Optimal Technique, Imaging Findings, and Management. RadioGraphics, 27, 357-369. https://doi.org/10.1148/rg.272065117

[5] Babak, J., Morteza, F.K., Mohammadeza, R., Anahta, A.D., Saleh, G., Belzad, L., et al. (2019) Characteristics of Traumatic Uro Genital Injuries in Emergency Department: A 10-Year Gross-Sectional Study. Archives of Academic Emergency Medecine, 7, 1-6.

[6] Bah, I., Diallo, A., Diao, B., N’doye, A., Gueye, S., Diallo, M., et al. (2006) Les lésions des organes génitaux externes par arme à feu. A propos de six observations à l'hôpital A. le Dantec, Dakar, Sénégal. African Journal of Urology, 12, 55-59.

[7] Ouattara, A., Avakoudjo, J., Hounnasso, P., Cisse, D., Hodonou, D., Gandaho, I., et al. (2013) Les urgences urologiques traumatiques au CHNU-HKM de Cotonou: Aspects épidémiologiques et thérapeutiques. A propos de 32 cas colligés en deux ans. Médecine d'Afrique Noire, 60, 396-401.

[8] Dje, K., Yao, B., Sanou, B., Kokoua, A. and Gnananzan, K. (2007) Les Complications urogénitales des traumatismes du bassin. A propos de 41 cas. Médecine d'Afrique Noire, 54. 53-59.

[9] Coulibaly, M., Issa, A., Kossogué, A. and Ouattara, Z. (2017) Traumatisme des bourses: Aspects cliniques et thérapeutiques au service d'urologie du CHU Gabriel Touré. Mali Médical, 32, 13-16.

[10] Kambou, O.A. and Zare, C. (2014) Traumatismes uro-génitaux: Profil épidémiologique et aspects lésionnels au centre hospitalier universitaire Souro. Sanon de Bobo Dioulasso (Burkina-Faso), 1, 83-90.

[11] Mohamed, A., Abdellatif, J., Ghadouane, M., Ameur, A., Mohamed, A., et al. (2014) Prise en charge des ruptures traumatiques des corps caverneux au sein d'une population militaire. Pan African Medical Journal, 18, Article No. 260.

https://doi.org/10.11604/pamj.2014.18.260.4732

[12] Gedik, A., Kayan, D., Yamis, S., Yilmaz, Y. and Bircan, K. (2011) The Diagnosis and Treatment of Penile Fracture: Our 19 Years Experience. Turkish Journal of Trauma \& Emergency Surgery, 17, 57-60. https://doi.org/10.5505/tjtes.2011.93763

[13] Kpatcha, T., Tengue, K., Botcho, G., Sikpa, K., Leoua, E., Sewa, E., et al. (2017) Notre expérience de la prise en charge de la fracture de la verge au CHU de Lomé. African Journal of Urology, 23, 342-346. https://doi.org/10.1016/j.afju.2017.02.004

[14] Andry, P., Nuno, G., Meuwly, J., Jichlinski, P. and Valerio, M. (2016) Prise en charge des traumatismes urogénitaux. Revue Médicale Suisse, 12, 2012-2016.

[15] Fuzier, R., Richez, A.S. and Olivier, M. (2007) Anesthésie locorégionale en urgence. Réanimation, 16, 660-664. https://doi.org/10.1016/j.reaurg.2007.09.028

[16] Morey, A., Brandes, S., Dugi, D., Armstrong, J., Breyer, B., Broghammer, J., et al. (2004) Urotrauma. AUA Guide Line. Journal of Urology, 192, 327-335. https://doi.org/10.1016/j.juro.2014.05.004

[17] Serafetinides, E., Kitrey, N., Djakovic, N., Kuehhas, F., Cumen, N., Sharma, D., et al. (2015) Review of the Current Management of Upper Unary Tract Injuries by the EAU Trauma Guide Lines Panel. European Urology, 67, 930-936. https://doi.org/10.1016/j.eururo.2014.12.034

[18] Pons, F., Rigal, S. and Dupeyron, C. (1997) Les plaies abdomino-pelvi-fessières de guerre. Principes du traitement. Urology Annals, 31, 294-302.

[19] Wolf, J., Turzan, C. and Caholica, E. (1993) Dog Bites to the Male Genitalia: Cha- 
racteristics, Management and Comparison with Human Bites. Journal of Urology, 149, 286-289. https://doi.org/10.1016/S0022-5347(17)36058-5

[20] Cummings, J. and John, B. (2000) Scrotal Dog Bites. Journal of Urology, 164, 57-58. https://doi.org/10.1016/S0022-5347(05)67448-4

[21] Gomes, C., Leopolao, R., Amilcar, M., Anuari, I., Estela, R. and Sami, A. (2000) Genital Trauma Due to Animal Bites. Journal of Urology, 165, 80-83. https://doi.org/10.1097/00005392-200101000-00020

[22] Leguillou, M., Pariente, J., Ferriere, J., Marie, J., Bouker, A., Hostyn, B., et al. (1996) Rupture traumatique de l'urètre, stratégie thérapeutique à propos de 122 cas. Chirurgie, 121, 367-371.

[23] Gueye, S., Ba, M., Sylla, C., N'doye, A., Diagne, B. and Mensah, A. (1992) Réparation en urgence différée des ruptures traumatiques de l'urètre postérieur. Andrologie, 2, 121-122. https://doi.org/10.1007/BF03034688

[24] Diallo, A., Bah, I., Bah, O., Amougou, B., Bah, M., Guirassy, S., et al. (2010) Le profil des urgences urologiques au CHU de Conakry. Progrès en Urologie, 20, 214-218. https://doi.org/10.1016/j.purol.2009.10.008

[25] Fall, B., Diao, B., Fall, P., Sow, Y., Ondongo, A., Diagana, M., et al. (2008) Les urgences urologiques en milieu hospitalier universitaire à Dakar: Aspects épidémiologiques, cliniques et thérapeutiques. Progrès en Urologie, 18, 650-653. https://doi.org/10.1016/j.purol.2008.04.004

[26] Cross, J.J., Berman, L.H., Elliott, P.G. and Irving, S. (1999) Scrotal Trauma: A Cause of Testicular Atrophy. Clinical Radiology, 54, 317-320. https://doi.org/10.1016/S0009-9260(99)90562-7

[27] Odzebe, A., Bouya, P. and Banga, M. (2009) Les traumatismes des bourses. African Journal of Urology, 15, 130-134. https://doi.org/10.1007/s12301-009-0022-7 